\title{
Critical Evaluation of the New Headway Advanced and the ILI Advanced Series: A Comparison of Curricular Components and CLT Objectives Based on ACTFL
}

\author{
Esmail Zare-Behtash (Corresponding author) \\ Chabahar Maritime University, Iran \\ E-mail: behtash@cmu.ac.ir \\ Hassan Banaruee \\ Chabahar Maritime University, Iran \\ E-mail: hassan.banaruee@gmail.com
}

\author{
Received: 01-03-2017 \\ Accepted: 09-05-2017 \\ Advance Access Published: July 2017 \\ Published: 01-09-2017 \\ doi:10.7575/aiac.ijalel.v.6n.5p.182 \\ URL: http://dx.doi.org/10.7575/aiac.ijalel.v.6n.5p.182
}

\begin{abstract}
The critical evaluation of systematic planning, development and review practices of instructional materials intend to improve the quality of teaching and learning. This study investigates the objectives of communicative language teaching and curricular components of two important textbooks which are widely studied in Iran: the New Headway Advanced Series (2015), the Iran Language Institute (ILI) Advancedl (2008). The evaluation is done in terms of two prospects; firstly, the interpretation of communicative language teaching objectives and secondly, curricular components of the books. To this aim, a checklist of $5 \mathrm{Cs}$ standards and seven curricular components evaluation developed by American Council on the Teaching of Foreign Languages (ACTFL) was employed. The evaluation reveals that the New Headway advanced series is more preferable and desirable than the ILI Advanced 1 due to the design and organization, authenticity, attractiveness, functionality, practicality and the other qualities mentioned above regarding communication, cultures, connection, comparison, and community in all aspects. The evaluation based on the seven curricular components- language systems, communication strategies, cultural knowledge, learning strategies, content from other subject areas, critical thinking skills, technology and the other features- indicates that the ILI textbook enjoys low standards and is not well developed in all components. The ILI textbook is highly reading and writing oriented and not appropriate for transactional and interactional learning purposes. This study acquaints language teachers and learners with the more desirable and cogent book.
\end{abstract}

Keywords: Curricular Components, Evaluation, Culture, the ILI Advanced, the New Headway Advanced

\section{Introduction}

There are three key factors in language classes: learners, teachers and textbooks. The textbooks are the most viable and adaptable ones, being investigated and updated in the field. Richards (2001) highlighted the role of textbook materials as the main instructional materials in most language courses. Learners with various learning styles have different needs and interests. Therefore, a one-fit-all textbook cannot account for all existence diversity. Every learner may consider the relevance and absorption with topics in the textbooks differently. It may also limit and inhibit teachers' creativity. The world today is bound to English learning and teaching. "Textbooks provide novice teachers with guidance in course and activity design; it assures a measure of structure, consistency, and logical progression in a class"(Wen-cheng et al., 2011). This study answers teachers in Iran whether the New Headway Advanced Series or the Iran Language Institute (ILI) Advanced is the most advantageous textbook appropriate to their course goals.

Kachru (1986) classified countries into three groups- the inner, outer and expanding circles: “The Inner Circle countries are the ones where English is the Native or major Language such as The United Kingdom. The Outer Circle countries are where English is considered the Second Language such as India. And the Expanding Circle; where English is studied as a Foreign Language such as Iran. People study English as a foreign language in Iran, in this respect Iran fits in the Expanding Circle." English has penetrated into the lives of people worldwide. Cook (2008) identified English as the world's sole 'hypercentral language' in this respect there is an absolute necessity in today's globalized world to learn English.

Although EFL curriculum materials have experienced drastic changes in recent years, the materials could not fulfill the expectations and needs of most learners and teachers. As a result, many of the students have not been able to use English effectively to communicate unlike many students join language classrooms in language institutes and study global materials besides the textbooks taught at school. "While the quality of ESL reading textbooks has improved 
dramatically in recent years, the process of selecting an appropriate text has not become any easier for most teachers and administrators" (Wen-cheng et al., 2011). In this respect they need scholars' contributions to provide them insights on the selection of the appropriate textbooks. Iran Language Institute where the ILI Advanced is being taught currently hardly employs modifications to its textbooks and methodology. To this aim this study provides great insight for the teachers, learners and principals involved with this institute in Iran.

Various criteria could be taken into account in order to have a critical evaluation of ELT textbooks. To the researchers' best knowledge; however, scarcely a study has been done to conduct an evaluative analysis of ELT textbooks according to the idea of American Council on the Teaching of Foreign Languages (ACTFL) in Iran. Savignon (as cited in Kumaravadivelu, 2006) argued that ACTFL standards represent a holistic, communicative approach to language learning and teaching. Kumaravadivelu (2006) defines 5 Cs of ACTFL standards as:

- The communication goal area addresses the learner's ability to use the target language to communicate thoughts, feelings, and opinions in a variety of settings;

- the cultures goal area addresses the learner's understanding of how the products and practices of a culture are reflected in the language;

- the connections goal area addresses the necessity for learners to learn to use the language as a tool to access and process information in a diversity of contexts beyond the classroom;

- the comparisons goal area are designed to foster learner insight and understanding the nature of language and culture through a comparison of the target language and culture with the languages and cultures already familiar to them; and

- the communities' goal area describes learners' lifelong use of the language, in communities and contexts both within and beyond the school setting itself. (p. 119)

These five Cs may be acceptable standards and widely used to evaluate textbooks. This critical evaluation also encompasses Harmer's (2001) concept of assessment. He indicated that the textbook assessment is typically a sort of evaluation done not inside classrooms. The identification of how well a new textbook performs in class and its evaluation is a judgment on how well a book has performed indeed. In the act of evaluation, teachers imply a key role; needless to say, they are the primary applicants of the books and have deep perceptiveness of their applicability and practicality. A meticulous evaluation enables the educational institution or organization to differentiate between all of the accessible textbooks on the market and choose the most appropriate one for their context.

The present study aimed to compare the New Headway Advanced (4th edition) and the ILI Advanced Series in terms of five goals in foreign language teaching and education; and also, the seven curricular elements based on ACTFL standards to find out similarities and differences of these series. Such a study is significant because it provides information especially for all Iranian English language training institutes, language-planners, language instructors, curriculum designers, teachers as well as learners to select their favorable textbook. In addition, results of this critical evaluation would hope to benefit English teachers in many of language institutes in that it might provide them insight into the textbook they require and how they may utilize it best.

\section{Review of the Related Literature}

It is necessary to provide some information about the context in which the compared English textbooks are employed. Iran as an Islamic country establishes yardsticks and rules regarding English language schools materials and logistic issues. All language schools are under the observation of the Ministry of Education in order to follow the yardsticks and stick to the norms. The majority of the EFL learners are kids, young adults and university students. Most of these language institutes teach textbooks which are published by famous publishers worldwide, yet sometimes manipulated by the Ministry of Education to be made appropriate to study in the context of Iran. The only language institute which publishes specific books prepared by experts in Iran is Iran Language Institute. This language institute is affiliated with the Ministry of Education and also is the biggest and oldest of all in Iran.

Since there are various appealing materials published by diverse companies, deciding on a selected one is a sophisticated job. So, textbook evaluation is inevitable in this process. Sohail (2011) argued that textbooks are indispensible elements in language teaching due to several reasons. There have been evaluations done over various textbooks which some of them are discussed in this study.

In a study based on Cunningworth's guidelines, Ranalli (2002) evaluated upper-intermediate New Headway and showed that it follows a PPP approach to learning- presentation, practice and production. And the units of the book do not provide a thorough authentic context for the patterns in the target language. The representation of gender in dialogues and job positions in both texts and examples of New Interchange Intro was studied by Dominguez (2003). She indicated that the textbook is a valuable source for teachers as its consideration of both cultural and multiracial settings. She also asserted that the textbook considered learners' settlement and integration needs properly, particularly at beginner levels, and provided a balance in the representation of the two genders.

The ILI Intermediate Series and Top Notch Intermediate were compared by Alemi and Isavi (2012) based on the specificities in the use of meta-discourse markers in Iran. Their study implied that all categories of interactional metadiscourse are used in both of the textbooks. However, among the different categories of interactional meta-discourse, self-mentions had the highest frequency in Top Notch Series and engagement markers were the most frequent ones in the ILI Series. 
As significant from the aforementioned studies the literature enjoys a good variety, yet lacks in the number which is a crystal clear indicator of the novelty of these types of comparative evaluations which makes the area very demanding. The two textbooks evaluated in this study were New Headway and the ILI advanced. In particular, the study investigated the answer to the question: Is there any difference between New Headway and the ILI advanced based on the ACTFL Standards? The standards include 5 C's (Communication, Cultures, Connections, Comparisons and Communities) and seven curricular elements (Language Systems, Communication Strategies, Cultural Knowledge, Learning Strategies, Content from Other Subject Areas, Critical Thinking Skills, Technology and Other Features).

\section{Methodology}

\subsection{Instruments}

The present study has employed three kinds of instruments including New Headway Advanced Series (fourth edition) authored by Liz Soars, John Soars and Paul Hancock (2015), the ILI Advanced 1 compiled and revised by the Iran Language Institute (ILI) Research and Planning Department (2008), and a checklist based on standards of American Council on the Teaching of Foreign Languages (ACTFL); first published Standards for Foreign Language Learning (1996). ACTFL employ 5C standards or 5Cs prominently known as communication, cultures, connection, comparison, and community; as well as, the seven curricular elements: language systems, communication strategies, cultural knowledge, learning strategies, content from other subject areas, critical thinking skills, technology and the other features.

\subsection{Data Collection Procedure}

The ACTFL checklists were filled out by 5 EFL teachers. They benefited from the teaching experience of at least one of the textbooks and were dominant on curriculum development. The checklists were gathered and descriptive analysis was calculated. The mode concluded from the descriptive analysis was represented in a checklist as the representative of all five checklists filled out.

\section{Data Analyses and Discussions}

The 5 C's table was dissected into five sections and discussed separately. The seven curricular components table was divided into seven tables and discussed in parts. A score for each item is suggested to judge the books based on the Standards' organizing principles and elements. The higher score goes for the better one. Then the total scores were compared to reach a conclusion to select the more desirable and cogent book.

Table 1.1 Evaluating according to the $5 \mathrm{c}$ 's (Communication)

\begin{tabular}{|c|c|c|}
\hline & BOOK & \\
\hline Communication (Section total: 20 points) & ILI Advanced & New Headway \\
\hline $\begin{array}{l}\text { 1. Are students introduced to essential vocabulary and grammatical structures? } \\
\text { (4pts.) }\end{array}$ & 2 & 4 \\
\hline $\begin{array}{l}\text { 2. Do the activities move from controlled to transitional to communicative? Is there } \\
\text { a balance between listening, speaking, reading, and writing? ( } 4 \text { pts.) }\end{array}$ & 1 & 4 \\
\hline $\begin{array}{l}\text { 3. Are there a variety of meaningful activities that provide opportunities for } \\
\text { individual, paired, cooperative learning, and information gap activities? ( } 4 \text { pts.) }\end{array}$ & 2 & 4 \\
\hline $\begin{array}{l}\text { 4. Are the activities set in an age-appropriate context and are they level- } \\
\text { appropriate? ( } 4 \text { pts.) }\end{array}$ & 3 & 3 \\
\hline $\begin{array}{l}\text { 5. Is there a spiraling presentation of concepts that builds in a perpetual review of } \\
\text { vocabulary and grammar concepts? ( } 4 \text { pts.) }\end{array}$ & 2 & 4 \\
\hline Subtotal & 10 & 19 \\
\hline
\end{tabular}

The ILI introduces 10 words at the beginning of each unit which is followed by a fill in the blanks exercise, some more vocabulary words are also introduced through reading section and 10 words in the post reading section but grammatical structures are not presented directly. This is mainly due to the nature of the ILI curriculum design and lesson plans, which make the learners, study grammar intensively in the high intermediate level and there is no section allocated to grammatical structures in advanced books.

New Headway introduces new vocabulary words with some explanation of their functions. The representation of vocabulary is significant as there are three to four sections within one unit allocated to vocabulary and the number of words represented in a vocabulary box supersedes the ILI's. As observable in one of the sections, the number of words was more than thirty. Moreover, it presents a specific grammar spot with some listening activities to clarify their essentiality and functionality. And as the language focus of the unit the grammatical structures are recursively presented in reading, listening and speaking sections in a spiral mode.

The ILI presents the 4 skills in 4 separate sections and it seems the activities are aimed to move from controlled to transitional to communicative relatively but it seems there is not that much balance between the 4 skills and the book seems more reading and writing based. Yet the nature of exercises and the time allocated to each skill is not well 
balanced and thoroughly controlled. Based on the methodology and syllabus provided for teachers which they have to do all accordingly, the syllabus for one session is as:

- Call the Roll

- Do Warming Up

- $\quad$ Check Reading the Passage

- $\quad$ Check Reading for Main Ideas

- Check Reading for Details

- Check Reacting to the Reading

- Do Developing the Topic

- Do Mini-Listening (the ILI Teacher's Book, 2008, p. 10)

The classes are held for 105 minutes, seems there is no balance, yet an imbalance between the skills being under focused. Headway is absolutely communicative and after introducing new subjects in a controlled way, provides some listening opportunities for the learners to listen and practice. The skills are found in mere equilibrium. Both are ageappropriate and level-appropriate.

The ILI provides a section called "progress check" after each three units and former lessons are also reviewed in the context of new lessons. This is more identical to a workbook exercise which is a supplementary to the exercises. Headway does not have any specific section as a check point, yet it is built on the grammatical, lexical and functional bases of previous levels and each unit contains a review of former lessons within the context. The exercises in the work book also include integrated and spiraling presentations of grammar and vocabulary.

Table 1.2 Evaluating according to the 5 c's (Cultures)

\begin{tabular}{lll}
\hline & BOOK \\
\hline Cultures (Section total: 10 points) & ILI Advanced & New Headway \\
\hline $\begin{array}{l}\text { 1. Are there wide varieties of authentic, up-to-date visual images of the target } \\
\text { culture? ( } 2 \text { pts.) }\end{array}$ & 0 & 1 \\
\hline 2. Is the cultural information age-appropriate to stimulate interest? (2 pts.) & 1 & 2 \\
\hline 3. Is a broad range and diverse representation of countries presented? (2 pts.) & 0 & 2 \\
\hline $\begin{array}{l}\text { 4. Does the teaching of the target culture incorporate the learners exploring their } \\
\text { own culture? ( } 2 \text { pts.) }\end{array}$ & 0 & 2 \\
\hline 5. Are both "Little c" and "Big C" culture represented? (2 pts.) & 1 & 9 \\
\hline Subtotal & 2 & 9 \\
\hline
\end{tabular}

The ILI fails to meet the readers with English culture so does not presents that much authentic-seeming, contemporary illustrations of the target culture. On the other hand, Headway is fully interested in different cultures and provides a variety of up-to-date, graphic images. Although the ILI is not very interested in the target culture, the topics chosen for the students are age appropriate relatively. Headway's cultural information is also age-appropriate and interesting.

The ILI does not provide a wide range and much representation of countries represented while Headway has a global view toward different cultures and this makes the book more interesting. The ILI tries to focus on less different cultural topics and prefers to present some general information about the big $\mathrm{C}$ such as art and general science. As Chastain (1988) argued people's life styles is the main concern of the little c culture, while the social, political and economic issues and the story of great people of a country are all dealt in the big $\mathrm{C}$ culture. Headway introduces different cultures and at the same time asks the students to compare them with their own native culture to talk or write about it. Headway presents more little $\mathrm{c}$ including daily life culture, social behavior, beliefs, housing, food and transportation.

Table 1.3 Evaluating according to the 5 c's (Connections)

\begin{tabular}{lll}
\hline & BOOK \\
\hline Connections (Section total: 10 points) & ILI Advanced & New Headway \\
\hline $\begin{array}{l}\text { 1. Are the students afforded opportunities to utilize the target language in } \\
\text { conjunction with other subject areas such as math and science? (5 pts.) }\end{array}$ & 3 \\
\hline 2. Are there themes that encourage cross-disciplinary projects? (5 pts.) & 2 & 4 \\
\hline Subtotal & 3 & 7 \\
\hline
\end{tabular}

Both textbooks provide themes that encourage cross-disciplinary projects such as business, advertisement, nature, earth, politics, theatre, schooling and economical issues. Yet no task is available to utilize the target language in conjunction 
with other subject areas such as math and science. However, learners studying New Headway are provided with some amazing videos available on i-tutor DVD-ROM. These videos are mostly scientific oriented and encourage crossdisciplinary projects.

Table 1.4 Evaluating according to the 5 c's (Comparisons)

\begin{tabular}{lll}
\hline Comparisons (Section total: 10 points) & BOOK \\
\hline $\begin{array}{l}\text { 1. Are students asked to look at their own native language and compare it } \\
\text { linguistically to the target language? ( } 5 \text { pts.) }\end{array}$ & ILI Advanced & New Headway \\
\hline $\begin{array}{l}\text { 2. Are students asked to compare their own culture and make comparisons with the } \\
\text { target culture to discover similar and different cultural concepts and patterns? (5 } \\
\text { pts.) }\end{array}$ & 5 \\
\hline Subtotal & 2 & 5 \\
\hline
\end{tabular}

None of the books ask students to compare the linguistic features in their native languages with the target language. The ILI does not ask the students to compare the target culture with their native culture, throughout the whole book only one task was found which questioned the learners, which was discuss to what extent you think that if the same research were done in your country, instead of the US, the results would be different. But New Headway frequently poses questions and topics, making challenges between cultural concepts and patterns.

Table 1.5 Evaluating according to the 5 c's (Communities)

\begin{tabular}{lll}
\hline Communities (Section total: 10 points) & BOOK \\
\hline $\begin{array}{l}\text { 1. Are students provided with role models or individuals who use foreign } \\
\text { languages in their lives for personal interest and enjoyment? (5 pts.) }\end{array}$ & ILI Advanced & New Headway \\
\hline $\begin{array}{l}\text { 2. Are students given examples of ways they can use their foreign language in the } \\
\text { future beyond the school experience? (5 pts.) }\end{array}$ & 5 \\
\hline Subtotal & 2 & 1 \\
\hline
\end{tabular}

The ILI provides neither much role model, nor much example of daily life opportunities to use the language, but presents more general topics even in speaking sections. The textbook is not prepared for personal discussions and experiences. It is profound with texts from various topics which do not follow communicative, content-based, taskbased or post method criteria. The texts and tasks indicate that learners are there to learn the language and about the language, not the use and usage. Headway presents plenty examples of real life activities such as greeting, negotiating, travelling, expressing thoughts and feeling, guessing and storytelling. Headway provides many examples of individuals who live abroad or travel a lot and use foreign languages.

Table 2.1 Evaluating according to the seven curricular components (Language Systems)

\begin{tabular}{llc}
\hline & BOOK \\
\hline Language Systems (Section total: 5 points) & ILI Advanced & $\begin{array}{l}\text { New } \\
\text { Headway }\end{array}$ \\
\hline 1. Is the vocabulary functional, thematic, authentic, and practical? (1 pt.) & 1 & 1 \\
\hline 2. Is the number of vocabulary words manageable? (1 pt.) & 0 & 1 \\
\hline 3. Is grammar presented in a logical way? (1 pt.) & 0 & 1 \\
\hline 4. Is there sufficient oral and written practice of the grammar concepts that lead from & 0 & 1 \\
controlled to meaningful to communicative use of the language? (1 pt.) & 0 & 1 \\
\hline 5. Is the grammar presented clearly and easy to understand? (1 pt.) & 5 \\
\hline Subtotal & & 1 \\
\hline
\end{tabular}

In terms of vocabulary both books represent good amount of words which are authentic, functional and practical in numerous themes. In respect with the manageability of the vocabulary tasks it seems with the sparse time allocation to this section in the ILI, learners are exposed to input-flooding within very short period of time (somewhat ten minutes), and no interactional or transactional activity is provided to the benefit of vocabulary learning. Regarding the grammar, 
the surprising part is where the ILI has no section provided for the sake of grammar. The remarkable characteristics of New Headway are highly outstanding. A congruent syllabus of all integrated materials as the practice of vocabulary and grammar is salient in all four skills tasks.

Table 2.2 Evaluating according to the seven curricular components (Communication Strategies)

\begin{tabular}{lcc}
\hline & BOOK \\
\hline Communication Strategies (Section total: 5 points) & ILI Advanced & $\begin{array}{l}\text { New } \\
\text { Headway }\end{array}$ \\
\hline $\begin{array}{l}\text { 1. Are listening, speaking, reading, writing, and cultural strategies (such as } \\
\text { circumlocution, making and verifying hypotheses, making inferences, and predicting) }\end{array}$ & 5 \\
presented and practiced? (5 pts.) & 2 & 5 \\
\hline Subtotal & 2 & 5 \\
\hline
\end{tabular}

A typical listening task in the ILI is: Listen and complete the chart below, or read the statements below. Listen again. Then circle the best answer. A typical Speaking task in the ILI is: Do you have stress full lives? Interview your partner. And then comes ten yes/no questions all beginning with "Do you...", or Look at the pictures/suggestions/statements and discuss with a partner, based on some general questions as "Which suggestion do you think is the most/least effective?" Regarding these two skills there is no strategy to the development of the skills. Yet regarding writing and reading skills various strategies are presented and practiced even more than the need of an EFL learner. All four skills and cultural strategies are presented and practiced in line with learners' skill development in an elaborate fashion. Making predictions, guesses, hypotheses and circumlocutions are presented and practiced in all units in New Headway advanced.

Table 2.3 Evaluating according to the seven curricular components (Cultural Knowledge)

\begin{tabular}{lll}
\hline & BOOK \\
\hline Cultural Knowledge (Section total: 5 points) & ILI Advanced & $\begin{array}{l}\text { New } \\
\text { Headway }\end{array}$ \\
\hline 1. Is the cultural content accurate and current? (3 pts.) & 1 & 3 \\
\hline $\begin{array}{l}\text { 2. Are the cultural notes/readings interesting, significant, and appropriate for the age } \\
\text { level? (2 pts.) }\end{array}$ & 2 \\
\hline Subtotal & 2 & 5 \\
\hline
\end{tabular}

The ILI textbook is somewhere away from accurate cultural content and does not represent either local or target cultural texts. There are some texts related to the big culture under topics as "Appreciating the Arts" or "Time is Money" and in discussions the learner may encounter some quotations from prominent characters such as Picasso, Adams, or Gandhi. The absence of visual images of the target culture and people's life styles is protruding. On the other side, Headway is fully interested in different cultures and provides a variety of genuine, contemporary vivid pictures. There are activities relevant to current cultural trends provided accurately and clearly practiced such as clips from the radio program "The Unbelievable Truth" a current popular clip on BBC. In contrast with the ignorance of culture in the ILI, there is a unit specified to culture clashes, stereotypes and nationalities in New Headway advanced which over 20 nations are involved in the exercises and activities.

Table 2.4 Evaluating according to the seven curricular components (Learning Strategies)

\begin{tabular}{lll}
\hline & \multicolumn{2}{l}{ BOOK } \\
\hline Learning Strategies (Section total: 5 points) & $\begin{array}{l}\text { ILI Advanced } \\
1\end{array}$ & $\begin{array}{l}\text { New } \\
\text { Headway }\end{array}$ \\
\hline $\begin{array}{l}\text { 1. Does the text provide the learners with strategies at point of use to help them be } \\
\text { successful listeners, speakers, readers, and writers of the language? (1 pt.) }\end{array}$ & 1 \\
\hline $\begin{array}{l}\text { 2. Are pair and cooperative learning activities plentiful and meaningful? (2 pts.) } \\
\text { 3. Are the multiple intelligences (such as visual, musical, and kinesthetic) utilized so as }\end{array}$ & 0 \\
to support the variety of learner types in the classroom? (2 pts.) & 0 & 2 \\
\hline Subtotal & 1 & 5 \\
\hline
\end{tabular}


Learners today are classified based on their learning strategies or styles in numerous categories. One of the most popular taxonomies are Ehrman and Leaver's (2003) which divides the learners, according to their learning styles, into two broad groups of ectenic and synoptic, including 20 sub-learning styles. This makes the current curriculum and material development a sophisticated and struggling profession. The ILI content representation and syllabus design is predictable after reading the first unit. This is so monotonous and fast-moulded that every learner thoroughly knows the task practice and production format and procedures. Even the learners can predict the types of questions which they are going to be asked or ask each other. For instance every reading task throughout the book includes post -reading exercises as:

- Reading for main ideas (Which choice best states the main idea in each paragraph?)

- Reading for details (Think about what you learned in the passage, and circle the best answer.)

- $\quad$ Reading to the reading (1. Match these words from the text with their definitions or synonyms on the right.2. Find matching pairs of sentences. Then write the appropriate letter in the space provided.)

This type of syllabus and material simply aims that if learners are pleased with and willing to learning in this way and context, which would be their fortune, yet what if they are dissatisfied with the strategies. Cheng (1988) argued that most students favor to learn in particular ways with each learning style contributing to the success in their intake. And concluded that students retain $10 \%$ of their reading, $26 \%$ of the hearing, $30 \%$ of their seeing, $50 \%$ of what they see and hear together, $70 \%$ of their saying, and $90 \%$ of what they say as they do something interactively. These findings revealed that learning styles may have strong points and weak points. Diversity of learners' learning styles indicates the diversity of outcomes in learning. The students who enjoy a multi-learning style tend to achieve higher scores compared to those who have fewer learning styles (Dunn, Beaudry \& Klavas 1989). Thus, this section is concerned with one of the utmost important ones.

In contradiction to the ILI, There are various strategies taken into consideration for the task preparation in New Headway. In order to have an even comparison between these two textbooks the reading task selection is acceptable. The diversity of strategies and techniques is magnificent, for instance the reading exercises in one unit are:

- Look at the four headings below. Use them to list some possible outcome of wars. Discuss ideas with the class.

- Read through the text quickly. Did you think of any of the things mentioned? Make a note of one important thing from each topic and discuss with the class.

- Read the text again. Look at the words below. Which heading do they go with?

- Answer the questions. (There are six reading comprehension questions)

- In your own words, what do these numbers refer to?

- What do you think? (There are some questions regarding the texts but open ended which the text information and learners personal knowledge must complement each other to discuss)

And the reading exercises in another unit are:

- Look at the map of Papua New Guinea. Do you anything about it? Discuss as a class which facts you think are true. (There is a list of eight facts available)

- Listen and check what extra information do you learn?

- Read the instruction to the article by the investigative journalist Donald MacIntyre. (There are some general questions about the text.)

- Read part one of the article. Use the prompts to talk to a partner in your own words. (it is a type of jigsaw task)

- Before you read part 2, work as a class to make a list of six questions you would most like answered. Then read and see which of your questions are answered.

- Are these statements true or false? Correct the false ones.

- Work out the meaning of the highlighted words from their contexts.

- What do you think? (There are some questions regarding the texts but open ended which the text information and learners personal knowledge must complement each other to discuss).

Table 2.5 Evaluating according to the seven curricular components (Content from Other Subject Areas)

\begin{tabular}{|c|c|c|}
\hline & BOOK & \\
\hline Content from Other Subject Areas (Section total: 5 points) & ILI Advanced & $\begin{array}{l}\text { New } \\
\text { Headway }\end{array}$ \\
\hline $\begin{array}{l}\text { 1. Are there activities/projects in every chapter/unit that engage the students in } \\
\text { meaningful activities that cross other disciplines where the students can use their } \\
\text { emerging language skills and see the connection with other disciplines? ( } 5 \text { pts.) }\end{array}$ & 2 & 4 \\
\hline Subtotal & 2 & 4 \\
\hline
\end{tabular}

The ILI textbook is abundant with rich readings and writing samples which contain a great deal of information. This information may come into practice in different ways. Similarly New Headway textbook provides learners with good information regarding different topics and as indicated in the aforementioned discussions there are even video clips 
provided to the benefit of such emerging language skills. The only contrast which emerges is that the ILI does not include this connection in the speaking and listening activities.

Table 2.6 Evaluating according to the seven curricular components (Critical Thinking Skills)

\begin{tabular}{|c|c|c|}
\hline & BOOK & \\
\hline Critical Thinking Skills (Section total: 5 points) & ILI Advanced & $\begin{array}{l}\text { New } \\
\text { Headway }\end{array}$ \\
\hline 1. Are students asked to do more than rote memorization and recall? ( 2 pts.) & 1 & 2 \\
\hline $\begin{array}{l}\text { 2. Are the students asked to utilize the higher order thinking skills of analysis, synthesis, } \\
\text { and evaluation in every chapter and are expectations reasonable? ( } 3 \text { pts.) }\end{array}$ & 1 & 3 \\
\hline Subtotal & 2 & 5 \\
\hline
\end{tabular}

In respect with reading and writing, the ILI is definitely beyond rote memorization and recall, as the syllabus highlights the role of learners in summarizing the reading texts and making an oral production of the text the following session. And while doing the writing activities learners are supposed to do hypothesis testing, paragraph development and organization. The book leads learners to effective paragraph writing indeed. Regarding the higher order thinking skills only the writing in the ILI is demanding, which is done as homework assignment. In contrast with the ILI, New Headway advanced is thoroughly thought provoking oriented and challenges different synthetic and analytic strategies to do the tasks inside the classroom. Most of the questions and discussions are involved with the "what do you think or discuss in your own words".

Table 2.7 Evaluating according to the seven curricular components (Technology)

\begin{tabular}{lll}
\hline & BOOK \\
\hline Technology (Section total: 5 points) & ILI Advanced & $\begin{array}{l}\text { New } \\
\text { Headway }\end{array}$ \\
\hline 1. Does the program have listening activities in the pupil's edition? (1 pt.) & 1 & 1 \\
\hline 2. Does the program have a video that is integrated with the text? (1 pt.) & 1 & 1 \\
\hline 3. Does the program have a CD-ROM that provides meaningful and interactive practice? & 0 & 1 \\
(1 pt.) & & 1 \\
\hline 4. Does the program have a website? (1 pt.) & 0 & 1 \\
\hline 5. Does the program suggest engaging, worthwhile Internet activities? $(1 \mathrm{pt})$. & 3 & 5 \\
\hline Subtotal & & 1 \\
\hline
\end{tabular}

The ILI advanced 1 covers listening activities in the book. This listening is included only in one section of each unit specified for listening and is not integrated with any other skills. There are only two films prepared for ILI which is about 10 minutes each and the time allotment for this part is only $70-90$ minutes throughout the term which takes for three months. There is no CD-ROM provided and the website is typically commercial and provides no pedagogical support to the benefit of learners. However, New Headway contains listening throughout the whole book and there are plenty of movies available on the CD-ROM, which all the video clips are integrated with the texts provided in the book. There is a web-site which supports learners and teachers worldwide and a lot of internet activities which may even support other learners studying some other courses.

Table 2.8 Evaluating according to the seven curricular components (Other Features)

\begin{tabular}{lll}
\hline & BOOK \\
\hline Other Features (Section total: 5 points) & ILI Advanced & $\begin{array}{l}\text { New } \\
\text { Headway }\end{array}$ \\
\hline $\begin{array}{l}\text { 1. Is the general appearance of the text and accompanying ancillaries attractive and } \\
\text { inviting? (1 pt.) }\end{array}$ & 1 & 1 \\
\hline 2. Are the chapters/units well organized and offer easy progression? (1 pt.) & 1 & 1 \\
\hline $\begin{array}{l}\text { 3. Is the teachers' edition well organized with practical teaching suggestions at the point } \\
\text { of need? (1 pt.) }\end{array}$ & 1 \\
\hline $\begin{array}{l}\text { 4. Is the program easily adaptable to fit different teaching situations or schedule } \\
\text { configurations? (1 pt.) }\end{array}$ & \\
\hline $\begin{array}{l}\text { 5. Does the testing program assess all four skills plus culture? Does it offer native } \\
\text { speaker exams, scantron, multiple forms of exams, and portfolio? (1 pt.) }\end{array}$ & 1 \\
\hline \begin{tabular}{l} 
Subtotal \\
\hline
\end{tabular} & 3 \\
\hline
\end{tabular}


Both textbooks are accompanied by supplementary materials books, workbooks, teachers' guides, CDs and videos. An experienced teacher and a novice teacher may find their ways best while teaching these two books for the significant well organized materials. Scantrons are available to be applied on the exams, yet there are not multiple forms of exams, and portfolios. In neither of the assessments all four skills are included. Mostly formative assessment is applied throughout the course which enables the teachers help the learners identify their strengths and weaknesses specifically on speaking and writing. Summative assessment is applied for reading and listening on the final exam accompanied with some sections regarding vocabulary and grammar. The conspicuous contrast in this section is where Headway is highly adaptable to fit various teaching situations, while the ILI follows strict linear methodology which the book is also provided in line with the underlying methodology.

\section{Conclusions}

The evaluation based on the five Cs standards indicated that New Headway advanced is more preferable and desirable than the ILI advanced due to the design and organization, authenticity, attractiveness, functionality, practicality and the other qualities mentioned above regarding communication, cultures, connection, comparison, and community in all aspects. These standards will provide communicative language teaching with discoursal and sociocultural features of language use argued in Kumaravadivelu (2006).

The evaluation based on the seven curricular components- language systems, communication strategies, cultural knowledge, learning strategies, content from other subject areas, critical thinking skills, technology and the other features- indicated that the ILI textbook enjoys low standards and is not well developed in all components. The ILI textbook is highly reading and writing oriented and not appropriate for transactional and interactional learning purposes. The textbook is locally used and the syllabus design is far from ACTFL standards.

It was concluded that New Headway advanced (fourth edition) enjoys a congruent syllabus of all integrated materials as the practice of vocabulary and grammar is salient in all four skills tasks. All four skills and cultural strategies are presented and practiced in line with learners' skill development in an elaborate fashion. The textbook is fully interested in different cultures and provides a variety of authentic, up-to-date vivid images. There are activities relevant to current cultural trends provided and practiced accurately, in contrast with the ignorance of culture in the ILI.

In contradiction to the ILI, There are various strategies taken into consideration for the task preparation in New Headway. The diversity of strategies and techniques is magnificent. Both textbooks are accompanied by supplementary materials books, workbooks, teachers' guides, CDs and videos available on the CD-ROM. There is a web-site and a lot of internet activities which support learners and teachers worldwide.

This study may provide implications for language teachers and learners to be familiarized to the nature of CLT objectives and curricular components of the evaluated textbooks. And the critical evaluation discussed in the current study may give insight to a more preferable and cogent textbook in Iran and the places where the books are available. This may also help learners and teachers select their language institutes to study and teach respectively.

\section{References}

Alemi, M., \& Isavi, E. (2012). Evaluation of interactional metadiscourse in EFL textbooks. Advances in Asian Social Science (AASS), 2(1), 422-430.

American Council on the Teaching of Foreign Languages (1996). Textbook Evaluation Based on ACTFL Standards. Alexandria, Virginia 22314.

Chastain, K. (1988). Developing second language skills: Theory and practice (3rd ed.). USA: Harcourt Brace Jovanovich.

Cook, V. (2008). Second language learning and language teaching (4th ed.). UK: Hodder Education.

Dominguez, L. M. (2003). Gender textbook evaluation. MA thesis, Centre for English Language Studies, University of Birmanham.

Dunn, R., J. Beaudry, and A. Klavas. (1989). Survey of research on learning styles. Educational Leadership March, 5058.

Harmer, J. (2001). The Practice of English language teaching. Essex: Pearson Education Limited.

Kachru, B. B. (1986). The alchemy of English: The spread functions and models of non-native Englishes. Oxford: Pergamon.

Kumaravadivelu, B. (2006). Understanding language teaching: From method to postmethod. Mahwah, New Jersey: Lawrence Erlbraum Associates.

Iran Language Institute, (2008). The ILI English Series, Advanced 1: Student's Book. ILI Research and Planning Department, ISBN 964-7747-47-0

Ranalli, J. C. (2002). An Evaluation of New Headway upper-intermediate. University of Birmingham. Soars, L., Soars, J., \& Hancock, P. (2015). New Headway Student's Book. Oxford University Press.

Sohail, A. (2011). The Procedure of textbook development in Pakistan. Available at: http://www.scribd.com/doc/60627513/Importance-of-Textbook,

Wen-Cheng., W. , H. Chien, L. and C. Chung, L., 2011. Thinking of the textbook in the esl/efl classroom. English Language Teaching, 4(2), 91-96. 